\title{
O PROCESSO DE BRICOLAGEM NA CRIAÇÃO DE HISTÓRIAS EM QUADRINHOS DE SUPER-HERÓIS
}

\author{
THE PROCESS OF BRICOLAGE IN THE CREATION \\ OF SUPERHERO COMICS
}

\section{EL PROCESO DE BRICOLAJE EN LA CREACIÓN DE LOS CÓMICS DE SUPERHÉROES}

1 Doutorando em Ciências Sociais pela Pontifícia Universidade Católica de São Paulo. E-mail: lobo@ibest.com.br 
RESUMO: Partindo da constatação de que as histórias em quadrinhos de super-heróis são consideradas por muitos autores como verdadeiras mitologias modernas, o presente artigo pretende estabelecer a relação entre o modo de operar do pensamento mítico com a criação dessas narrativas, analisando as reflexôes de autores em histórias em quadrinhos, sobre seu próprio ofício, a partir do conceito de bricolagem de Lévi-Strauss.

ABSTRACT: Based on the observation that superhero comics are considered by many authors as true modern mythologies, this article intends to establish the relation between the way mythical thinking operates with the creation of these narratives, analyzing the reflections of authors in comics, about their own craft, from Lévi-Strauss's concept of bricolage.

RESUMEN: A partir de la evidencia de que las historietas de superhéroes son consideradas por muchos autores verdaderas mitologías modernas, este artículo pretende establecer la relación entre el modo de operar del pensamiento mítico con la creación de sus narrativas y analizar las reflexiones de autores en cómics acerca de su propio oficio a la luz del concepto de bricolaje de Lévi-Strauss.

PALAVRAS-CHAVE: Mito; Super-Heróis; Quadrinhos.

IKEYWORDS: Myth; Super heroes; Comics.

PALABRAS CLAVE: mito, superhéroes; cómics

O presente artigo busca analisar o caráter mítico das histórias em quadrinhos de super-heróis a partir da ideia de bricolagem estabelecida pelo antropólogo Claude LéviStrauss, que criou tal conceito com base na analogia entre o pensamento mítico e o trabalho de um bricoleur. Dessa maneira, busca-se compreender a possível relação existente entre a forma como o pensamento mítico opera para organizar os elementos de sua narrativa e o modo como os autores de histórias em quadrinhos criam e elaboram as narrativas de superheróis.

As histórias em quadrinhos de super-heróis são tratadas como mitologias modernas, tanto por parte de seus leitores, como por parte de seus autores, conforme mostra o escritor Brian J. Robb: “Stan Lee, editor e escritor da Marvel Comics, certa vez se referiu aos super- 
heróis como 'uma mitologia do século XX' que apresentava 'um mito inteiramente contemporâneo, uma família de lendas que pode ser passada para as futuras geraçóes’” (2017, p. 19-20).

$\mathrm{O}$ valor adquirido por esses personagens dos quadrinhos ganhou inclusive a atenção de intelectuais, que também passaram a enxergar nessas histórias semelhanças com as antigas narrativas mitológicas, como é o caso do pensador italiano, Umberto Eco, que afirmou, em seu livro Apocalípticos e Integrados (1990), que o Superman seria um ícone de uma mitologia moderna. Tal visão também é compartilhada pelo mitólogo romeno Mircea Eliade, segundo o qual: “os personagens dos comics strips (histórias em quadrinhos) apresentam a versão moderna dos heróis mitológicos ou folclóricos” (ELIADE, 1994, p. 159).

A maior parte dos autores, como Marco Arnaudo (2013), Brian J. Robb (2017) e Christopher Knowles (2008), que se dedicaram ao estudo das histórias em quadrinhos de super-heróis abordando sua proximidade com mitos antigos usam o conceito de arquétipo estabelecido pelo mitólogo Joseph Campbell (1997), que entende as imagens arquetípicas como ideias universais presentes no inconsciente coletivo. Por isso, as narrativas que trazem esse conteúdo possuem um caráter universal, no caso dos super-heróis sempre estaria presente a arquetípica "Jornada do Herói”, contudo essa universalidade dos mitos a partir de seu conteúdo é criticada por Lévi-Strauss (1974, p.20), que entende que a universalidade dessas narrativas não reside no conteúdo, mas na estrutura inconsciente dessas histórias, ou seja, nas operações simbólicas e não nas imagens arquetípicas.

A visão de Claude Lévi-Strauss sobre as narrativas míticas, além de reafirmar a universalidade dos mitos, resgatou o valor dessas histórias como verdadeiras expressôes de conhecimento, que podem ser vistas como elaboradas e sofisticadas formas dos povos antigos resolverem contradiçóes inerentes ao seu modo de viver, nessa perspectiva o mito funciona "como uma espécie de sistema cognitivo norteador das condutas individuais e grupais" (GAMA, 2013, p. 53).

Para Lévi-Strauss (1989) o pensamento mítico opera no plano intelectual de maneira semelhante a bricolagem no plano técnico, que tem por característica aproveitar 
um conjunto limitado de objetos para elaborar algo novo, reaproveitando tudo o que tem ao seu dispor que, embora possa ser abundante, permanece limitado. Criar algo inusitado, mas reaproveitando antigos objetos, esse é o desafio do bricoleur.

\begin{abstract}
Mesmo estimulado por seu projeto, seu primeiro passo prático é retrospectivo, ele deve voltar-se para um conjunto já constituído, formado por utensílios e materiais, fazer ou refazer seu inventário, enfim e sobretudo, entabular uma espécie de diálogo com ele, para listar, antes de escolher, entre elas, as respostas possíveis que o conjunto pode oferecer ao problema colocado. (LÉVI-STRAUSS, 1989, p. 35)
\end{abstract}

Os mitos trabalham com signos do mesmo modo que o bricoleur trabalha com objetos, pois os signos ficam em uma zona intermediária entre a imagem e o conceito, o que lhes dá uma característica interessante, pois “como a imagem, ele goza de concretude, mas assemelha-se ao conceito por causa de suas prerrogativas referenciais: um e outro não se fecham em si mesmos, sendo capazes de substituírem coisas alheias" (GAMA, 2013, p. 58).

Por isso é correto afirmar que o pensamento mítico atua sobre um conjunto heteróclito, mas limitado, pois os signos emprestados da linguagem podem ser ressignificados, mas não com liberdade total, além do que, qualquer escolha para atribuir um novo sentido vai obrigar a reorganização do todo, com resultado muitas vezes imprevisível.

A reflexão mítica sempre visa uma estruturação nova de conjuntos de fatos passados, ou fragmentos de fatos, que seriam nas palavras de Lévi-Strauss: "testemunhos fósseis da história de um indivíduo ou de uma sociedade” (1989, p. 38). Mas não se trata simplesmente de falar desses fatos, mas sim falar através dos fatos passados, ao fazer isso a reflexão mítica deixa uma marca indelével, contudo sem apagar as referências anteriores.

De maneira semelhante, ao reutilizar seus objetos, o bricoleur sempre deixa em sua obra um pouco de si, mas sem desrespeitar os usos pregressos do objeto. Gama exemplifica essa ideia levistraussiana da seguinte forma:

Um cubo de madeira, perante a insuficiência de tábuas corridas, serve de calço em algumas situaçôes, mas extrapolá-lo a todos os casos onde um calço seja requerido constitui um equívoco, porque a história de sua fabricação lhe outorgou propriedades inalienáveis. Além disso, as 
adaptaçóes que sofreu em virtude de outros usos anteriores também limitam as pretensōes de reempregá-lo indefinidamente, ainda que para finalidades parecidas. (GAMA, 2013, p. 58)

Nessa perspectiva, os mitos são constantemente reelaborados, a partir de fragmentos de universos pretéritos, tal atividade se desenvolve através de um olhar para trás, embora visando solucionar uma questão do presente, essa característica é fundamental para diferenciar o modo de pensar mítico do pensamento científico, para Lévi-Strauss:

O pensamento mítico, esse bricoleuse, elabora estruturas organizando os fatos ou os resíduos dos fatos, ao passo que a ciência, "em marcha" a partir da sua própria instauraçấo, cria seus meios e seus resultados sob a forma de fatos, graças as estruturas que fabrica sem cessar e que são suas hipóteses e teorias. (LÉVI-STRAUSS, 1989, p. 38)

A ciência, ao seu modo, conquistou um grande domínio sobre a natureza, pois procedeu de maneira menos abrangente, dividindo em partes o universo, seguindo um dos pilares do pensamento cartesiano, mas abrindo máo de um sentido universal para suas açóes. O pensamento mítico, de certa forma, é mais ambicioso do que o pensamento científico, segundo a visão levistraussiana, "porque su finalidad reside en alcanzar, por los medios más diminutos y económicos, una comprensión general del universo - y no sólo una compresión general, sino total” (LÉVI-STRAUSS, 2012, p. 44).

O conceito de bricolagem oferece uma excelente referencial teórico para a análise do processo de criação de histórias em quadrinhos de super-heróis, pois essas histórias foram criadas a partir de múltiplas referências do patrimônio da cultura e da subcultura ocidental, além de serem muitas vezes tratadas como mitologias modernas.

O Superman e o Batman são os personagens ideais para essa análise, por serem os pioneiros desse gênero de histórias, servindo de referência e inspiração para todos os superheróis posteriores, já que ambos "deram origem a um gênero triunfante. A maioria dos super-heróis se enquadra em algum ponto na escala entre esses dois, que são naturalmente opostos de tantas formas" (ROBB, 2017, p. 13). 
A criação do Superman pode ser considerada como um eficiente trabalho de bricolagem, pois os seus autores, Jerry Siegel e Joe Shuster, retiraram suas inspiraçóes de elementos culturais da tradição judaico-cristã e greco-romana, talvez as duas principais tradiçóes que formaram a cultura ocidental, em outras palavras, o personagem seria a atualização de mitos antigos, trazendo esses elementos para o mundo contemporâneo.

De acordo com Brian Robb, o Superman é uma criação baseada em vários mitos, com destaque para as histórias de personagens da tradição judaico-cristã, como Jesus e Moisés, ambos destinados a salvar o mundo, mesma missão assumida pelo Superman, que se tornou o protetor da "humanidade (essencialmente os Estados Unidos, como ficou claro durante a Segunda Guerra Mundial) a salvo do mal" (ROBB, 2017, p. 43), ao mesmo tempo, a concepção do herói é um resgate da mitologia greco-romana, de acordo com a visão de Grant Morrison:

Superman era o renascimento de nossa ideia mais antiga: ele era um deus. Seu trono encima dos picos do emergente Olimpo das bancas e, assim como Zeus, ele disfarçava-se como mortal para caminhar entre as pessoas comuns e ter contato com seus dramas e sofrimentos. Os paralelos prosseguem: Seu S é um relâmpago estilizado - a arma de Zeus, a flecha motivadora da autoridade austera e do devido castigo. (MORRISON, 2012, p. 33)

A criação de um novo mito, a partir de fragmentos de mitos anteriores não é uma tarefa fácil, pois é preciso considerar que "o peso relativo dos mitos nas memórias coletivas em muito depende da forma com que os conjuntos de signos perfilados em uma dada narrativa são desalojados de suas tessituras e revitalizados na articulação de outro" (GAMA, 2013, p. 59).

Desse modo, a junção de elementos de uma tradição abundante, porém limitada, para construir uma narrativa de super-heróis, através de uma linguagem que une o texto e a imagem, se assemelha ao modo de operação do pensamento mítico, que cria suas histórias por meio da bricolagem de elementos heteróclitos, que, se for realizada com eficiência, pode adquirir o caráter de um novo mito, embora seu processo sempre se volte para elementos do passado. 
Além da criação do herói ser a bricolagem de vários elementos presentes em vários mitos, escrever histórias do Superman ou do Batman, super-heróis icônicos e clássicos, é uma tarefa difícil, pois, apesar de os autores precisarem escrever uma narrativa nova a cada edição, não podem criar algo que desrespeite a identidade do personagem.

Nesse sentido, Grant Morrison, que já escreveu histórias para vários super-heróis, demonstra que, para os autores, é um grande desafio criar narrativas inéditas para um personagem tão icônico quanto o Superman: "Temos que nos adaptar as suas regras se entramos em seu mundo. Nunca podemos transformá-lo demais, ou vamos perder o que ele é" (MORRISON, 2012, p.31).

A afirmação de Morrison demonstra a semelhança entre o autor de histórias em quadrinhos e o bricoleur, que precisa criar algo inusitado reinventando o uso de um material já utilizado anteriormente, e fazendo isso deixa sua marca, mas sem estabelecer algo definitivo, que não possa ser alterado, como afirma Lévi-Strauss: "Sem jamais completar seu projeto, o bricoleur sempre coloca nele alguma coisa de si” (1989, p. 38).

A seguinte afirmação de Lévi-Strauss: "Não pretendemos, portanto, mostrar como os homens pensam nos mitos, mas como os mitos se pensam nos homens, e à sua revelia" (1991, p.21), pode ser percebida na reflexão de Morrison sobre como se sente escrevendo histórias do Superman: "Na verdade, é como se ele fosse mais real do que nós. Nós roteiristas, somos substituídos a toda hora, as geraçóes de artistas deixam suas versóes e ainda algo persiste, algo que sempre é Superman” (2012, p. 31). Os super-heróis dos quadrinhos como narrativas de valor coletivo ultrapassam os limites do indivíduo e acabam atingindo o universal.

O conjunto de elementos que forma o universo do herói não pode ser alterado rapidamente, os autores variam o conteúdo de maneira gradativa, sem grandes saltos, mas quando ocorrem grandes mudanças, as editoras permitem que isso ocorra durante um período de tempo, para depois retornar ao que era antes.

Esse processo poderia ser descrito como uma interferência externa, que exige do mito uma nova resposta para um problema posto pela própria coletividade. Essa 
interferência tenta adulterar o mito, transformando radicalmente seus elementos, nos quadrinhos essas mudanças são facilmente percebidas na alteração drástica de visual.

O arco de histórias conhecido no Brasil como a Queda do Morcego é um bom exemplo dessas mudanças radicais para responder uma necessidade externa nova, que exige a transformação do mito, que trava um verdadeiro combate com a chegada de elementos novos, capazes de sacudir e alterar um universo mitológico já sedimentado.

De acordo com esse $\operatorname{arco}^{2}$, um viláo chamado Bane, que usa uma substância chamada "veneno" para aumentar sua força física, executa um elaborado plano para derrotar o Batman. Esse plano consiste em libertar vários criminosos, para cansar o herói com inúmeras perseguições e lutas. Os objetivos de Bane são atingidos, o homem-morcego fica completamente exausto. Aproveitando o momento de fragilidade, o vilão ataca, e, após uma luta desigual, quebra a coluna do Batman (Figura 1).

Figura 1: Bane quebra a coluna de Batman

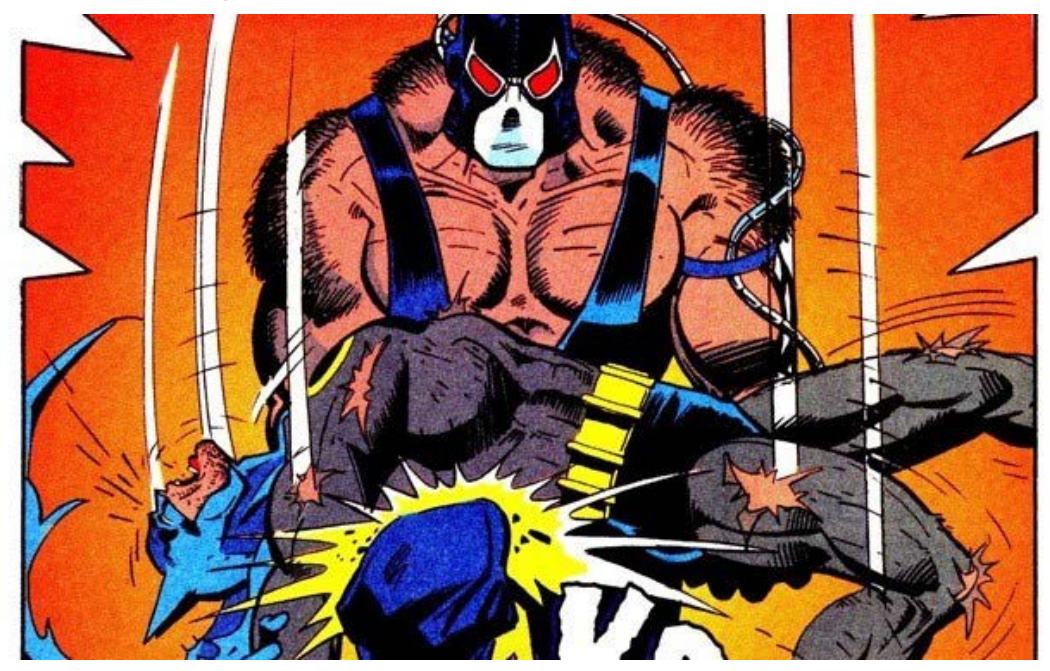

Esse evento tem como resultado a ascensão de um novo Batman, chamado JeanPaul Valley, enquanto Bruce Wayne, o alter ego original do herói, passa a procurar formas de curar sua coluna. Jean-Paul Valley era um dos assistentes do Batman original, mas antes

2 Conjunto de edições de uma revista que narram uma mesma história. 
de se tornar um aliado, tinha sido um anti-herói chamado Azrael, membro de uma ordem secreta conhecida como São Dumas.

Como Batman, Jean-Paul Valley saiu-se bem no início, trazendo vitalidade e energia ao personagem, mas com o passar do tempo, alterou o uniforme do personagem mesclando elementos de sua armadura dos tempos de Azrael (Figura 2) com o traje do próprio Batman, o visual agressivo (Figura 3) refletia o aumento da violência do personagem, que chegou ao ponto de deixar morrer um dos malfeitores que enfrentou.

Figura 2: Azrael

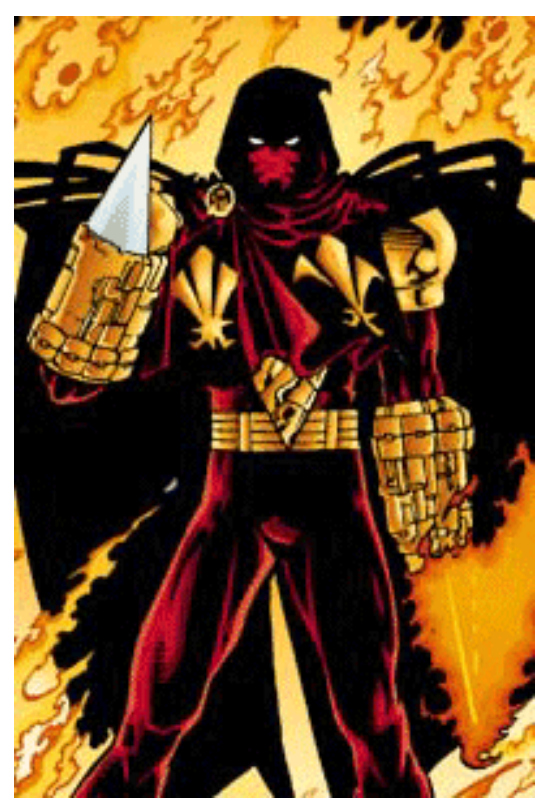

Figura 3: Novo Batman

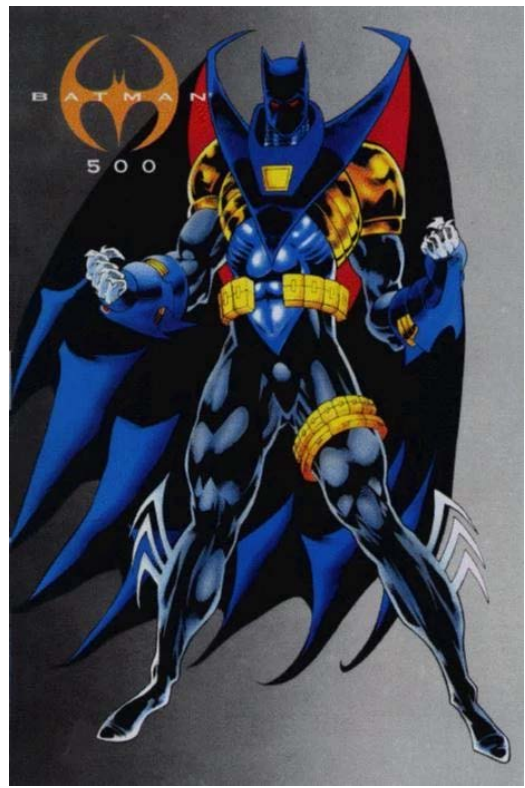

Tais eventos tornaram evidente a necessidade do retorno de Bruce Wayne, que havia conseguido restaurar sua coluna fraturada. O desfecho da história é uma épica luta entre Jean-Paul Valley contra Bruce Wayne, vencida pelo Batman original, que reestabelece os elementos centrais que definem o personagem, inclusive o visual.

A grande questão a ser levantada seria, qual força pressionaria a transformação de um personagem tão icônico quanto o Batman e também que forças contribuíram para que o mito do homem-morcego continuasse a existir. O autor Matthew K. Manning explica o contexto desse movimento de destruição e resgate: 
Com a predominância de personagens extremamente violentos em outras editoras, o editor Dennis O' Neil questionou o que aconteceria se Batman tivesse essa mesma característica. Foi assim que O’Neil e sua equipe criaram o conceito de $A$ Queda do Morcego. Os fãs, no entanto, não acolheram a ideia de um Batman radical por muito tempo. Daí surgiu O retorno do Morcego. (2015, p. 208)

A chegada de um novo conjunto de heróis que obrigou autores do Batman a repensarem o personagem é semelhante ao contato entre povos diferentes, no qual um determinado povo vê sua vida e sua cultura mudarem radicalmente com a chegada de um elemento invasor, como por exemplo, o contato entre índios e europeus, segundo Gama:

Mitos heroicos de diversas etnias indígenas sul-americanas incorporaram idiossincrasias judaico-cristãs, gerando a partir daí um novo rol de práticas ritualísticas e míticas com traços sincréticos de ambos. Essa fusão fez com que tanto a trajetória dos heróis mitológicos indígenas como dos mártires católicos emergisse com novas perspectivas. (GAMA, 2013, p. 57).

Entretanto, é difícil, mesmo diante de uma certa pressão externa, alterar um personagem táo tradicional do universo dos quadrinhos como o Batman, que, assim como o Superman, é um dos melhores exemplos de bricolagem bem sucedida. Para Grant Morrison, o personagem é "claramente produto da astúcia aplicada, veloz, mas astutamente rejuntando a partir de uma mistura de detritos da cultura pop que, reunidos, transcendiam a soma de suas partes" (MORRISON, 2012, p. 35). Desse modo, Bob Kane ao criar o Batman agiu como um bricoleur intelectual que "se volta para uma coleção de resíduos de obras humanas, ou seja, para um subconjunto da cultura” (LÉVI-STRAUSS, 1989, p. 36). 


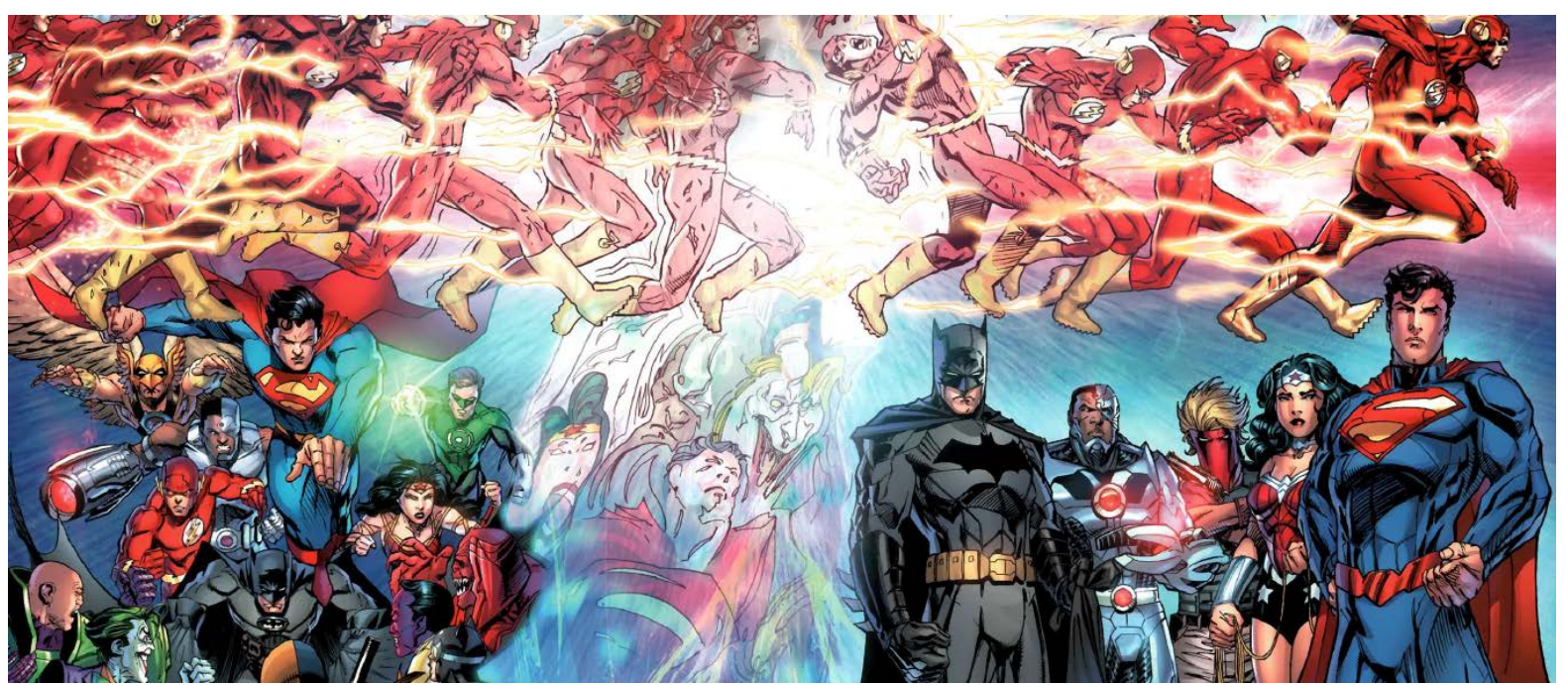

Figura 4: Flash alterando a linha cronológica do Universo DC em Ponto de Ignição

O processo de bricolagem é recorrente nos quadrinhos, principalmente quando personagens antigos precisam ser atualizados, ou repensados, recentemente o Superman passou por uma atualização tão interessante quanto fracassada. Em 2011, a DC Comics decidiu estabelecer um novo universo para seus super-heróis, a partir das alteraçôes cronológicas promovidas pelas viagens no tempo do Flash (Figura 4) na série Ponto de Ignição (2017), o universo que surgiu passou a ser chamado de novos 52.

Nesse contexto, um dos personagens clássicos que mais sofreu alterações foi o Superman, não tanto em relação à sua origem, mas em relação à sua personalidade, pois o herói foi rejuvenescido, tornando-se mais impulsivo e emotivo. Grant Morrison, que participou da criação desse novo Superman, definiu o personagem da seguinte forma:

Acima de tudo, o que eu sempre digo é que a gente deixou ele um pouquinho mais homem. (risos) Acho que é a melhor coisa que podia ter acontecido. Agora ele tem mais atitude; não é mais um cara do sistema. Ele ficou mais perigoso. Ficou mais emotivo. Ele pode ficar furioso; tem senso de humor. Clark Kent também não é mais só o pateta do interior. Ele também tem coisas que quer realizar. (MORRISON apud ASSIS, 2013)

Contudo, esse novo Superman não teve o sucesso esperado, pois essa reinterpretação do herói acabou distanciando os fấs mais tradicionais do personagem, apesar de ter 
atualizado elementos que já tinham se transformado em motivo de risos, como a famosa cueca vermelha por cima da calça azul (Figura 5).

Figura 5: Superman Novos 52

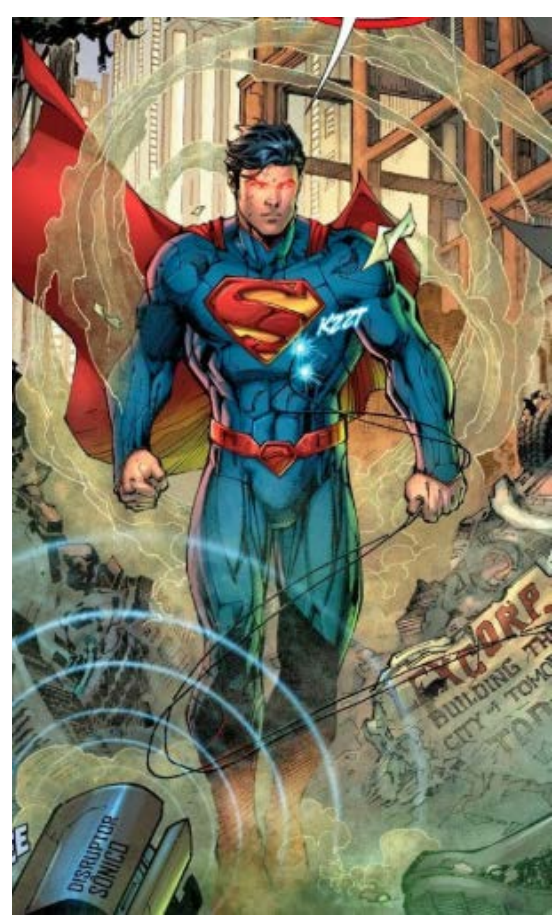

Figura 6: Superman com poderes diminuídos

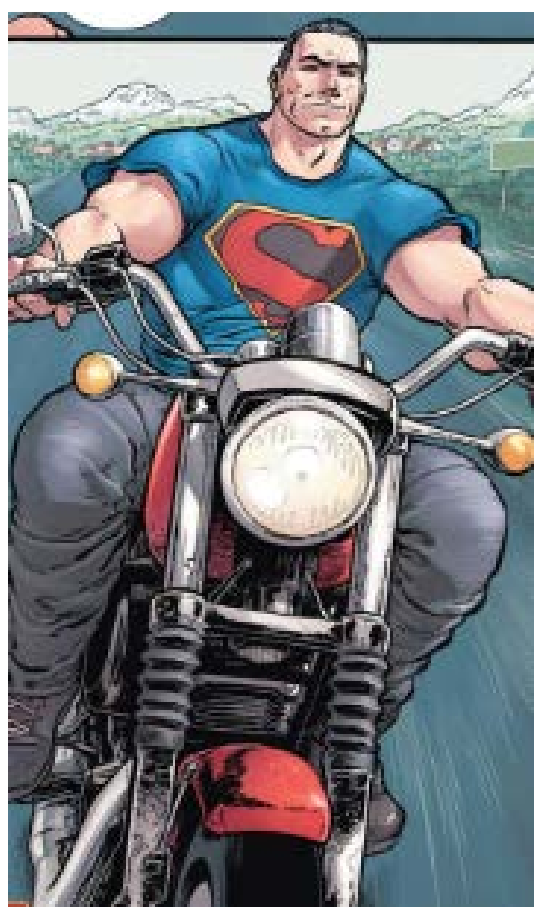

O fato é que o universo dos novos 52 não teve o resultado de vendas esperado, mas alguns personagens sofreram mais, como é o caso do Superman, que foi rejuvenescido, tornou-se um ser poderoso e impulsivo, para depois perder parte dos seus poderes e adquirir o visual de um valentáo (figura 6), para no fim recuperar o visual e os poderes e morrer lutando contra uma espécie de sósia solar (imagem 7), tudo isso ocorreu com um alarde semelhante à importância dessa fase do herói, ou seja, muito pequeno. 


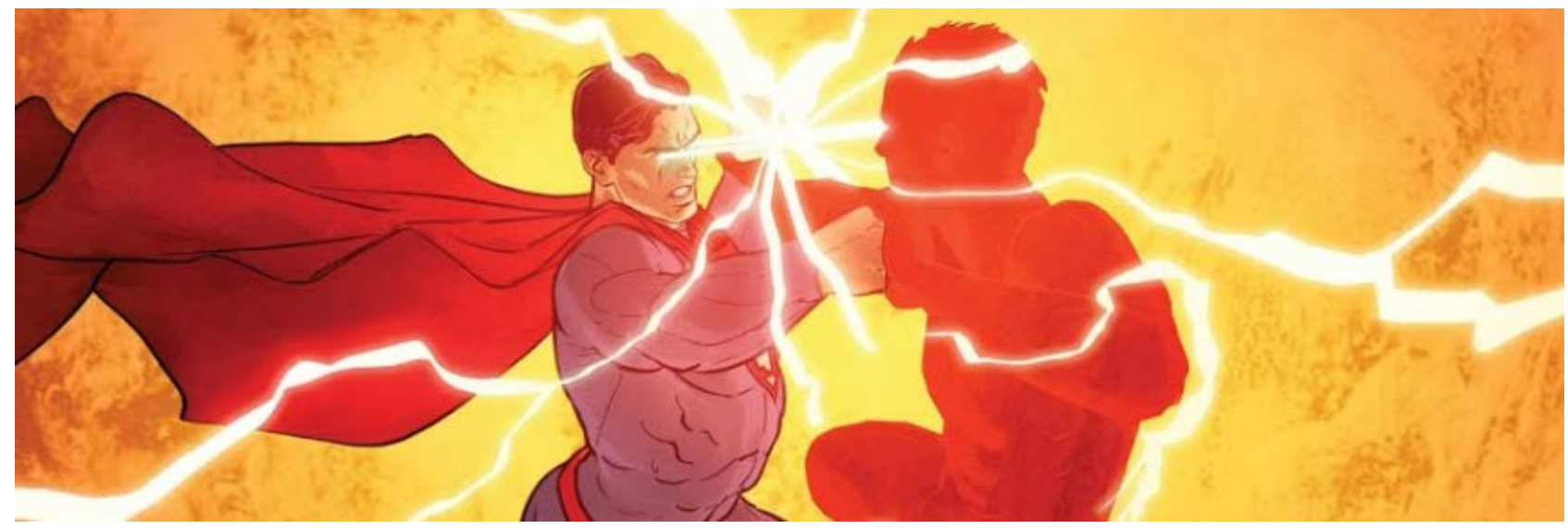

Figura 7: Superman: luta final

Contudo, é relevante o modo como o Superman tradicional, aquele que havia sido apagado pela era dos novos 52, conseguiu retornar ao universo DC. Em uma série chamada Convergência (2016), os leitores ficaram sabendo que alguns universos, que todos pensavam que estavam destruídos, tinham sido preservados, algumas cidades estavam intactas, nesse contexto ressurgiu o Superman tradicional, sua história inclusive tinha progredido, sua mulher, Lois Lane, estava grávida e deu à luz durante a série. O Superman tradicional e sua família conseguiram escapar desse banimento e foram trazidos para o universo dos novos 52, permanecendo ocultos até a morte do novo Superman, quando o Homem de Aço tradicional volta a usar seu uniforme.

É importante perceber a evolução do uniforme desse Superman tradicional, o modo como evoluiu - dispensando o uniforme preto, brevemente usado enquanto o personagem estava oculto do público. É interessante notar que o visual do Superman dos novos 52 influenciou o uniforme adotado pelo Superman tradicional em seu retorno (Figura 9), pois antes do Ponto de Igniçãa o uniforme usado pelo personagem era o clássico (Figura 8).

Essas mudanças poderiam ser consideradas apenas alteraçóes estéticas, entretanto, o processo de bricolagem pode ser reconhecido, pois é possível perceber de maneira clara, que nada é destruído nas histórias em quadrinhos, elementos são deixados para trás para mais adiante serem retomados, olhando para o passado as peças são rearranjadas. 
No caso estudado, tal processo é evidenciado quando o Superman tradicional, ao entrar em um universo que lhe é estranho, teve que se adaptar, escolhendo um novo uniforme, mas, ao mesmo tempo, o personagem trouxe consigo toda carga de seu universo anterior, desse modo é claro que surgiria um conflito, mas a editora resolveu tal impasse através da síntese, criando uma narrativa na qual tanto o Superman tradicional, quanto o Superman dos novos 52 seriam a mesma pessoa, só que foram divididos por uma artimanha do duende Mxyzptlk, ser da quinta dimensão, o resultado óbvio foi a fusão entre os elementos antigos com os novos, dando origem a um novo Superman unificado (Figura $10)$.

Figura 8:

Superman pré-Novos 52

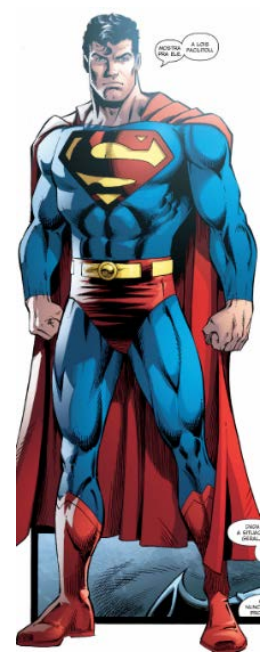

Figura 9:

Superman restaurado

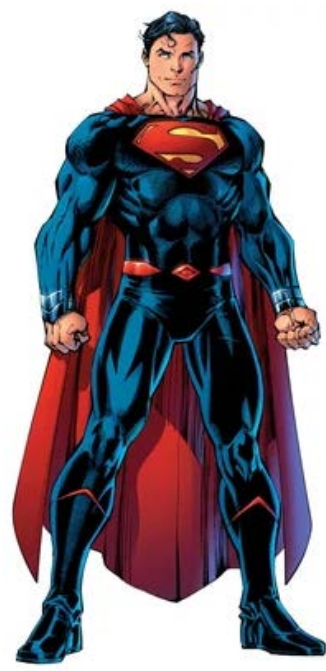

Figura 10:

Superman unificado

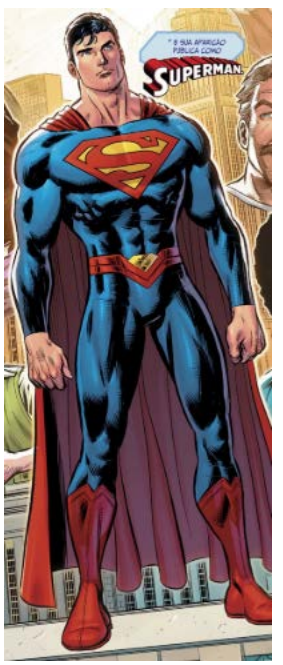

Desta forma, o bricoleour, o pensamento mítico e o autor de histórias em quadrinhos teriam o mesmo modelo operativo na elaboração de suas obras, tal conclusão é importante para analisar o valor mítico das histórias em quadrinhos de super-heróis em sua estrutura narrativa e não somente em seu conteúdo, como normalmente ocorre com os autores que pretendem estabelecer essa relação. 
A grande semelhança reside justamente no fato de que o bricoleur, o pensamento mítico e o autor de história em quadrinhos precisam sempre se preocupar com o passado, pois não são completamente livres para criar qualquer coisa, porque cada mudança exige pensar na repercussáo que terá em todo o conjunto, que pode ser um sucesso, ou um terrível fracasso.

Contudo, é importante destacar que existem especificidades, embora o modus operandi seja o mesmo, o bricoleur aproveita um material usado em outros projetos para elaborar algo inusitado, para resolver uma necessidade presente. $\mathrm{O}$ pensamento mítico usa elementos limitados, os signos, que são retirados da linguagem, na qual já possuem determinados significados que, embora possam ser alterados, devem ser compensados com a alteração de todo o conjunto. O autor de história em quadrinhos de super-heróis lida com personagens criados há muitos anos, que surgiram da bricolagem de vários mitos, mas que constituíram ao longo dos anos um universo próprio, que não pode ser alterado completamente, principalmente em relação aos valores e ao visual do herói, pois caso as mudanças sejam muito grandes podem afetar o valor icônico do personagem. 


\section{REFERÊNCIAS}

ARNAUDO, M. The myth of superhero, translated by Jamie Richards, Baltimore: The Jonh Hopkins Press, 2013.

ASSIS, E. Grant Morrison explica como a personalidade de Superman mudou nos Novos 52. Omelete, 13 fev. 2013. Disponível em <https://omelete.com.br/quadrinhos/noticia/grantmorrison-explica-como-personalidade-de-superman-mudou-nos-novos-52/>. Acessado em: 30 abr. 2018.

CAMPBELL, J. O herói de mil faces, tradução Adail Ubirajara Sobral, São Paulo: Editora Pensamento, 2007.

CONVERGÊNCIA: Superman. Barueri: Panini Comics, s.n., mar. 2016.

ECO, U. Apocalípticos e integrados, 4a Ed., tradução de Pérola de Carvalho, São Paulo: Editora Perspectiva, 1990.

ELIADE, M. Mito e realidade, 4a Ed., tradução Pola Civelli, São Paulo, Editora Perspectiva, 1994

GAMA, D. R. N. Do mito à alegoria: Revisitando os caminhos do pensamento selvagem em Lévi-Strauss, Revista Filosofia Capital, Vol. 8, Ed. 15, 2013.

JOHNS, G. Flash: ponto de ignição, São Paulo: Eaglemoss, 2017.

KNOWLES, C. Nossos deuses são super-heróis: a história secreta dos super-heróis das histórias em quadrinhos, tradução Marcello Borges, São Paulo: Cultrix, 2008.

LÉVI-STRAUSS, C. O pensamento selvagem, $11^{\text {a }}$ Ed., trad. Tânia Pellegini, Campinas: Papirus, 2010.

- O cru e o cozido: Mitológicas, trad. Beatriz Perrone-Moisés, São Paulo: Editora Brasiliense, 1989.

Mito y Significado, 3aEd., traducción Héctor Arruabarrena, Madrid: Alianza Editorial, 2012.

. "Introdução à obra de Marcel Mauss" In: MAUS, M. Sociologia e antropologia, São Paulo: EPU, 1974.

MANNING, M. K. Batman: Arquivo histórico, São Paulo: Panini Books, 2015.

MORRISON, G. Superdeuses, tradução Érico Assis, São Paulo: Seoman, 2012. 
ROBB, B. J. Identidade secreta dos super-heróis: a história e as origens dos maiores sucesso das HQs: do Super-Homem aos Vingadores, trad. André Gordirro, Rio de Janeiro: Valentina, 2017.

\section{FONTES DAS FIGURAS}

Figura 1 - Bane quebra a coluna de Batman

Fonte: Disponível em: <http://www.legiao42.com.br/wp-content/uploads/2017/07/bat man-knightfall1.jpg>. Acessado em: 13 out. 2017

Figura 2 - Azrael

Fonte: Disponível em: <https://static.comicvine.com/uploads/original/1/19151/459823azrael.gif>. Acessado em: 13 out. 2017.

Figura 3 - Novo Batman

Fonte: Disponível em: <https://vignette2.wikia.nocookie.net/batman/images/4/41/Azraelbatman_01.jpg/revision/latest?cb=20090613190027 >. Acessado em: 13 out. 2017.

Figura 4 - Flash alterando a linha cronológica do Universo DC em Ponto de Ignição Fonte: JONHS, 2017, s.p.

Figura 5 - Superman Novos 52

Fonte: LIGA DA JUSTIÇA, Barueri: Panini, no 1, mar. 2014, s.p.

Figura 6 - Superman com poderes diminuídos

Fonte: SUPERMAN, Barueri: Panini, no. 41, abri. 2016, s.p.

Figura 7 - Superman luta final

Fonte: SUPERMAN: FIM DOS DIAS, Barueri: Panini, mar. 2017, s.p.

Figura 8 - Superman pré-Novos 52

Fonte: CONVERGÊNCIA: SUPERMAN, Barueri: Panini, s.n., mar. 2016, s.p.

Figura 9 - Superman Restaurado

Fonte: Disponível em: <http://wonder-woman.wikia.com/wiki/Superman>. Acessado em: 30 mai. 2018

Figura 10 - Superman Unificado

Fonte: ACTION COMICS, Barueri: Panini, nº11, fev. 2018, s.p. 